\title{
Optimizing Cancer Care Delivery through Implementation Science
}

\author{
Taiwo Adesoye*, Caprice C. Greenberg and Heather B. Neuman \\ Department of Surgery, University of Wisconsin School of Medicine and Public Health, Madison, WI, USA
}

The 2013 Institute of Medicine report investigating cancer care concluded that the cancer care delivery system is in crisis due to an increased demand for care, increasing complexity of treatment, decreasing work force, and rising costs. Engaging patients and incorporating evidence-based care into routine clinical practice are essential components of a high-quality cancer delivery system. However, a gap currently exists between the identification of beneficial research findings and the application in clinical practice. Implementation research strives to address this gap. In this review, we discuss key components of high-quality implementation research. We then apply these concepts to a current cancer care delivery challenge in women's health, specifically the implementation of a surgery decision aid for women newly diagnosed with breast cancer.

OPEN ACCESS

Edited by:

Sarah M. Temkin,

National Cancer Institute, USA

Reviewed by:

Christos Markopoulos, University of Athens, Greece

Paul N. Mainwaring,

ICON Cancer Care, Australia

*Correspondence:

Taiwo Adesoye

taiwo.adesoye@gmail.com

Specialty section:

This article was submitted to

Women's Cancer,

a section of the journal

Frontiers in Oncology

Received: 30 November 2015 Accepted: 03 January 2016 Published: 28 January 2016

Citation:

Adesove T, Greenberg CC and Neuman HB (2016) Optimizing Cancer Care Delivery through Implementation Science.

Front. Oncol. 6:1.

doi: 10.3389/fonc.2016.00001
Keywords: implementation science, dissemination and implementation research, cancer care delivery, breast cancer, knowledge-to-action, decision aid

\section{INTRODUCTION}

The 2013 Institute of Medicine report investigating cancer care concluded that the cancer care delivery system is in crisis due to an increased demand for care, increasing complexity of treatment, decreasing work force, and rising costs (1). The proposed conceptual framework for a high-quality cancer delivery system highlights the importance of engaging patients and their families, providing evidence-based care, and translating the evidence into routine clinical care. In the current system, translating beneficial research findings to the real world health-care setting is often slow and haphazard despite the proven benefits $(2,3)$. It has been suggested that an average of 17 years elapses before $14 \%$ of original research is integrated into routine physician practice (Figure 1) (4). This gap between the identification of beneficial research findings and the application in clinical practice has led to an increased focus on the processes for implementing new knowledge and the rapidly growing field of dissemination and implementation (D\&I) science (5-9). Eccles and Mittman defined implementation research as "the scientific study of methods to promote the systematic uptake of research findings and other evidence-based practices into routine practice" (10). Implementation research spans implementation ("the use of strategies to adopt and integrate evidence-based health interventions and change practice patterns within specific settings") and dissemination ("the targeted distribution of information and intervention materials to a specific public health or clinical practice audience") (11). From past experiences, it is clear that those traditional, passive modes of implementing and disseminating evidence-based practices, such as publication in journals and development of consensus statements, are generally ineffective in sustainably integrating research findings into routine practice $(5,12)$. Therefore, systematic efforts to identify active, theory-driven implementation strategies are essential $(4,13-17)$. 


\section{The "Pipeline" Concept of Disseminating Research to Get Evidence-Based Practice*}

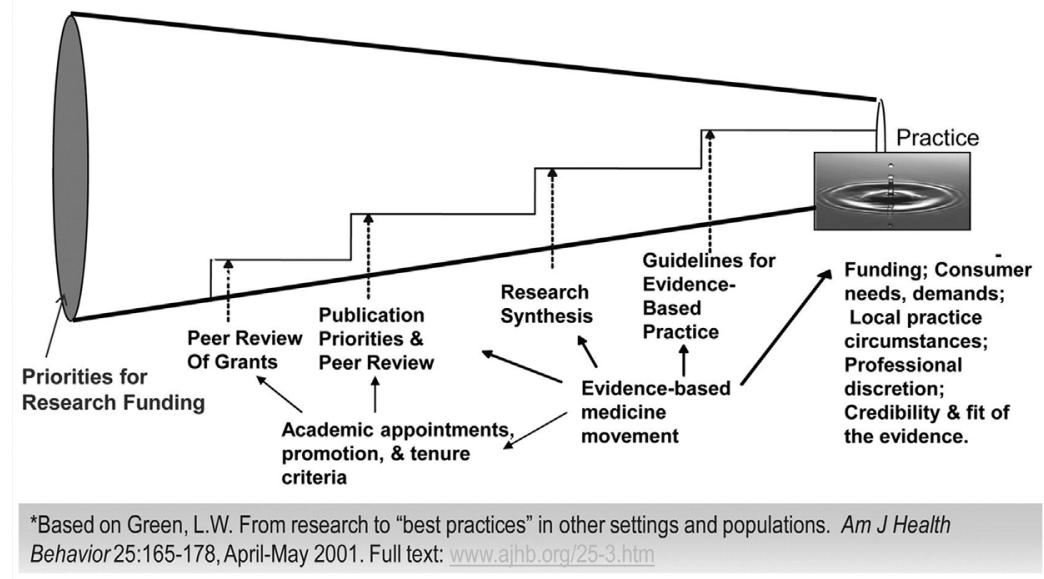

FIGURE 1 | The pipeline of production and translation of knowledge generated from research into routine clinical practice includes a series of successive screens designed to assure that high-quality research products are delivered to end users. However, this process results in only $14 \%$ of original research being integrated into routine clinical practice and does little to assure that the research products are relevant and/or useful to end users. From Green (5) with permission.

\section{THEORETICAL FRAMEWORKS}

Early implementation research was largely "trial and error" with only a minority (10\%) of studies providing a theoretical rationale for their approach (18). The absence of a theoretical framework supporting early implementation efforts combined with lack of common terminology to describe processes made it difficult to predict the success of an implementation approach or for others to reproduce the process in other settings (19). A theory-driven approach to implementation that explores explicitly the link between an intervention and an outcome, and systematically strives to explain why the intervention worked or failed in a particular setting is critical to understand and operationalize the key implementation steps $(7,18,19)$. In addition to facilitating the implementation for a specific intervention, this type of systematic approach will lead to the creation of generalizable knowledge surrounding methods for the sustainable implementation of an intervention across studies and settings. Theoretical models that broadly inform implementation research are multidisciplinary, pulling from the fields of medicine, public health, psychology, marketing, political science, and even agriculture. In 2011, more than 60 models to support D\&I research had been utilized in the literature (20). Considerable effort has been made to consolidate these theories and models to provide researchers with a guide in identifying conceptual models that would best support their work. For example, Tabak et al categorized the theories and models relevant to D\&I research according to their focus on dissemination and/or implementation activities and the socio-ecological level to which they are applicable (20). They also rated the flexibility of the model constructs, ranging from a score of 1 (very loose construct definition allowing researchers maximal flexibility in applying the model) to 5 (more defined constructs providing researchers with a more operational, stepby-step approach to D\&I research activities). Examples of these categorizations for some commonly used models are presented in Table 1.

Two often used frameworks to guide implementation efforts include the consolidated framework for implementation research (CFIR) (21) and the RE-AIM framework (8). The CFIR focuses primarily on implementation. It synthesizes existing constructs from multiple published implementation theories into an overarching typology that can be used to conduct a diagnostic assessment of the implementation and context, track the progress of implementation, and explain the success (or lack of success) of an implementation strategy (21). Included constructs focus on the characteristics of the intervention, such as its source, complexity, or cost; the outer setting, such as relevant governmental policies and regulations or external pressure from competing organizations; the inner setting, such as structural characteristics of an organization, organizational culture, and organization readiness for implementation; the characteristics of involved individuals, such as their knowledge and beliefs about an intervention and their belief in their ability to implement the intervention; and the process of implementation, including planning the implementation, engaging key individuals, and evaluating the implementation efforts. Researchers can select relevant constructs from this framework to guide assessment of their intervention and monitor implementation progress. By contrast, the RE-AIM framework is an evaluation framework with an equal focus on implementation and dissemination (8). It guides evaluation of the Reach of an intervention (is the intervention getting to the target population), Effectiveness (is 
TABLE 1 | Categorization of commonly used dissemination and implementation models [adapted from Tabak et al. (20)].

\begin{tabular}{|c|c|c|c|c|c|c|c|}
\hline & \multirow{2}{*}{$\begin{array}{l}\text { Dissemination and/ } \\
\text { or implementation }\end{array}$} & \multirow{2}{*}{$\begin{array}{l}\text { Construct flexibility: loosely } \\
\text { defined to highly structured } \\
\text { constructs (scale 1-5) }\end{array}$} & \multicolumn{5}{|c|}{ Socio-ecological level } \\
\hline & & & System & Community & Organization & Individual & Policy \\
\hline RE-AIM (8) & $D=1$ & 4 & & $x$ & $x$ & $x$ & \\
\hline $\begin{array}{l}\text { Consolidated framework for } \\
\text { implementation research (21) }\end{array}$ & I-only & 4 & & $x$ & $x$ & & \\
\hline $\begin{array}{l}\text { Framework for knowledge } \\
\text { translation (22) }\end{array}$ & D-only & 5 & & $x$ & $x$ & $x$ & \\
\hline Normalization process theory (23) & I-only & 3 & $x$ & $x$ & $x$ & $x$ & \\
\hline $\begin{array}{l}\text { Health promotion research center } \\
\text { framework (24) }\end{array}$ & $D>1$ & 4 & & $x$ & $x$ & $x$ & $x$ \\
\hline The precede-proceed model (25) & $D=1$ & 5 & & $x$ & $x$ & $x$ & \\
\hline $\begin{array}{l}\text { Replicating effective programs plus } \\
\text { framework (26) }\end{array}$ & I-only & 4 & & $x$ & $x$ & & \\
\hline
\end{tabular}

D, dissemination; l, implementation.

the intervention effective in the real world setting), Adoption (are target groups adopting the intervention), Implementation [what is the fidelity, i.e., the degree to which the intervention is implemented as originally intended (9)], and Maintenance or sustainability (are the effects of the intervention maintained over time) (8). This type of evaluation framework can then facilitate comparisons between different interventions and methods of implementation and can inform both the choice of intervention and the needed implementation strategies.

\section{SELECTION OF IMPLEMENTATION STRATEGIES}

Dissemination and implementation theoretical models provide a systematic approach to developing and evaluating the implementation of interventions. Within these frameworks, specific implementation strategies can be selected that match the needs of a clinical program or practice $(16,17)$. These strategies vary in nature and complexity from a single component (such as reminders, educational meetings) to multifaceted designs, which include multiple discrete or interwoven strategies $(5,16,17)$. Compilations of strategies and specific definitions of each strategy have been created to provide researchers with a mechanism for the identification of important and feasible options to meet the needs of their study. Using concept mapping in a multi-stage project known as the expert recommendations for implementing change (ERIC), Waltz et al. grouped 73 implementation strategies into 9 main clusters with similar conceptual backgrounds (Table 2) (17). The importance and feasibility of each strategy were then rated by experts in the field of implementation science. This type of compilation allows researchers to compare and prioritize different strategies most likely to be successful in their clinical context. Although further work must be done to examine the validity of these groupings, this represents an important resource for researchers developing and implementing interventions.

When considering implementation strategies, it is critical to consider the context in which an intervention will be implemented.
TABLE 2 | Implementation strategies organized by cluster by Waltz et al. showing mean importance and feasibility ratings provided by a panel of implementation science and clinical experts.

\begin{tabular}{|c|c|c|c|}
\hline $\begin{array}{l}\text { Implementation } \\
\text { strategy cluster }\end{array}$ & Importance & Feasibility & $\begin{array}{l}\text { Example of a strategy } \\
\text { rated as both } \\
\text { important and feasible }\end{array}$ \\
\hline $\begin{array}{l}\text { Use evaluative and } \\
\text { iterative strategies }\end{array}$ & 4.19 & 4.01 & $\begin{array}{l}\text { Provide audit and } \\
\text { feedback }\end{array}$ \\
\hline $\begin{array}{l}\text { Provide interactive } \\
\text { assistance }\end{array}$ & 3.67 & 3.29 & Facilitation \\
\hline $\begin{array}{l}\text { Adapt and tailor to } \\
\text { context }\end{array}$ & 3.59 & 3.30 & $\begin{array}{l}\text { Tailor implementation } \\
\text { strategies }\end{array}$ \\
\hline $\begin{array}{l}\text { Develop stakeholder } \\
\text { interrelationships }\end{array}$ & 3.47 & 3.64 & $\begin{array}{l}\text { Inform local opinion } \\
\text { leaders }\end{array}$ \\
\hline $\begin{array}{l}\text { Train and educate } \\
\text { stakeholders }\end{array}$ & 3.43 & 3.93 & $\begin{array}{l}\text { Conduct educational } \\
\text { meetings }\end{array}$ \\
\hline Support clinicians & 3.23 & 3.06 & $\begin{array}{l}\text { Facilitate relay of clinical } \\
\text { data to providers }\end{array}$ \\
\hline Engage consumers & 3.25 & 2.95 & $\begin{array}{l}\text { Involve patients/ } \\
\text { consumers and family } \\
\text { members }\end{array}$ \\
\hline $\begin{array}{l}\text { Utilize financial } \\
\text { strategies }\end{array}$ & 2.86 & 2.09 & a \\
\hline Change infrastructure & 2.40 & 2.01 & a \\
\hline
\end{tabular}

The importance rating scale ranged from 1 (relatively unimportant) to 5 (extremely important), and the feasibility scale ranged from 1 (not at all feasible) to 5 (extremely feasible).

${ }^{a}$ No implementation strategies in these clusters were rated to be both important and feasible.

The real world clinical environment is subjected to contextual factors, unlike the controlled research settings in which evidencebased interventions are often designed and tested (27-30). Contextual factors influence the success of implementation and strategies may need to be modified or additional strategies added to address the unique needs of local sites. These factors are recognized at different levels of the implementation process, such as the individual level, including team interactions and individual skill 
sets, and the organizational level, where available resources and degree of managerial support for a particular intervention may vary between sites (29). Utilizing active, multifaceted implementation strategies in a manner that considers the local context and aligns with organizational priorities increases the potential of efforts being successful.

\section{REPORTING INTERVENTION IMPLEMENTATION}

To ensure adequate description of intervention implementation, a number of guidelines for specifying and reporting details of interventions and the implementation processes used have been created (Table 3) (19, 31-38). The goal of these initiatives was to increase the ability of others to deliver an intervention as originally intended, resulting in better fidelity and potentially leading to improved outcomes. Included as a requirement in many of these guidelines are details of not only the intervention itself but also the implementation process such as descriptions of who administered the intervention, the mode of intervention delivery, how the intervention's implementation may have been adapted to the local context, and how fidelity to the original intervention was maintained $(31-33,36-38)$. It is important to also describe the context in which an intervention was implemented. While utilizing this type of systematic approach to intervention development is necessary, extending its use in reporting both successful and unsuccessful interventions is critical to creating generalizable knowledge which will lead to improved care delivery.

Using theoretical models to guide intervention development, identifying active implementation strategies perceived to be feasible and important, and considering the local context in which an intervention will be implemented increase the likelihood that an intervention will be successfully implemented and sustained. To highlight further how these concepts can be applied to a contemporary clinical problem relevant to women's health, we discuss challenges and potential solutions to the implementation and dissemination of patient decision aids, focusing specifically on a breast cancer surgery decision aid.

\section{BREAST CANCER SURGERY DECISION AIDS}

Decision aids are a form of decisional support designed for use as an adjunct to clinical consultation and can facilitate patientdriven decision-making by clarifying and contextualizing the medical and psychological issues associated with the decision $(39,40)$. The Affordable Care Act promotes the routine use of decision aids to improve shared decision-making and decrease unwarranted variation in care and cost (41). Many decisions for cancer treatment require patients to consider the risks and benefits of various treatments in the context of their personal values, making them especially appropriate for application of a decision aid. Consider breast cancer surgery: as survival is equivalent for both breast conservation and mastectomy, women must weigh the increased risk of recurrence associated with breast conservation against the greater impact on body image associated with mastectomy in order to make a decision that matches their personal values. Active patient participation in this decision is essential, as it is associated with less decisional regret, more satisfaction with care, improved post-operative body image, and greater long-term quality of life (42-44). Breast cancer surgery decision aids effectively support this decision-making process by improving knowledge, decreasing decisional conflict, and facilitating communication between patients and surgeons (44-47). Unfortunately, despite their proven effectiveness and perceived ease of use, only a minority of women diagnosed annually with breast cancer receive one during the course of their care $(48,49)$. The current limited reach of evidence-based decision aids into the everyday care of cancer patients represents an ideal example where the application of implementation science can lead to improved delivery of cancer care.

TABLE 3 | Overview of available reporting guidelines for the implementation of interventions.

\begin{tabular}{|c|c|c|}
\hline Reporting guideline & Method of development & Goal of guideline \\
\hline $\begin{array}{l}\text { Workgroup for intervention development } \\
\text { and evaluation research (WIDER) group } \\
\text { recommendations (31) }\end{array}$ & Expert recommendations to journal editors & $\begin{array}{l}\text { Describes extensions to the CONSORT guidelines that } \\
\text { will facilitate better communication of behavioral change } \\
\text { interventions }\end{array}$ \\
\hline $\begin{array}{l}\text { Template for intervention description and replication } \\
\text { (TIDieR) checklist (32) }\end{array}$ & $\begin{array}{l}\text { Created through expansion of CONSORT criteria } \\
\text { using a modified Delphi consensus approach }\end{array}$ & $\begin{array}{l}\text { Describes a } 12 \text { item checklist to improve the completeness } \\
\text { of reporting of interventions to improve replicability }\end{array}$ \\
\hline $\begin{array}{l}\text { Criteria for reporting the development and } \\
\text { evaluation of complex interventions in health care } \\
(\mathrm{CReDECl} 2)(33)\end{array}$ & $\begin{array}{l}\text { Created through a systematic literature review and } \\
\text { expert review }\end{array}$ & $\begin{array}{l}\text { Describes a criteria list of } 16 \text { items pertaining to the } \\
\text { reporting of the (1) development, (2) feasibility and } \\
\text { pilot testing, and (3) introduction of an intervention and } \\
\text { evaluation }\end{array}$ \\
\hline Intervention taxonomy (ITAX) (34) & $\begin{array}{l}\text { Researcher review of intervention study protocols } \\
\text { to capture key elements of the interventions } \\
\text { important to subsequent replication }\end{array}$ & $\begin{array}{l}\text { Describes a taxonomy/catalog of key features of an } \\
\text { intervention to consider in design, execution, and reporting }\end{array}$ \\
\hline $\begin{array}{l}\text { Strengthening the reporting g of observation } \\
\text { studies in epidemiology (STROBE) statement (35) }\end{array}$ & $\begin{array}{l}\text { Created during a 2-day workshop with } \\
\text { methodologists, researchers, and journal editors }\end{array}$ & $\begin{array}{l}\text { Describes a checklist of } 22 \text { items to guide reporting of } \\
\text { observational research }\end{array}$ \\
\hline $\begin{array}{l}\text { Standards for quality improvement reporting } \\
\text { excellence (SQUIRE 2.0) }(36,37)\end{array}$ & $\begin{array}{l}\text { Created with input from an expert panel with } \\
\text { public feedback }\end{array}$ & $\begin{array}{l}\text { Outlines a checklist of items to consider when reporting } \\
\text { quality improvement studies }\end{array}$ \\
\hline Standards for reporting implementation studies of & Created by multidisciplinary panel using an & Describes standards for reporting of implementation studies \\
\hline
\end{tabular}




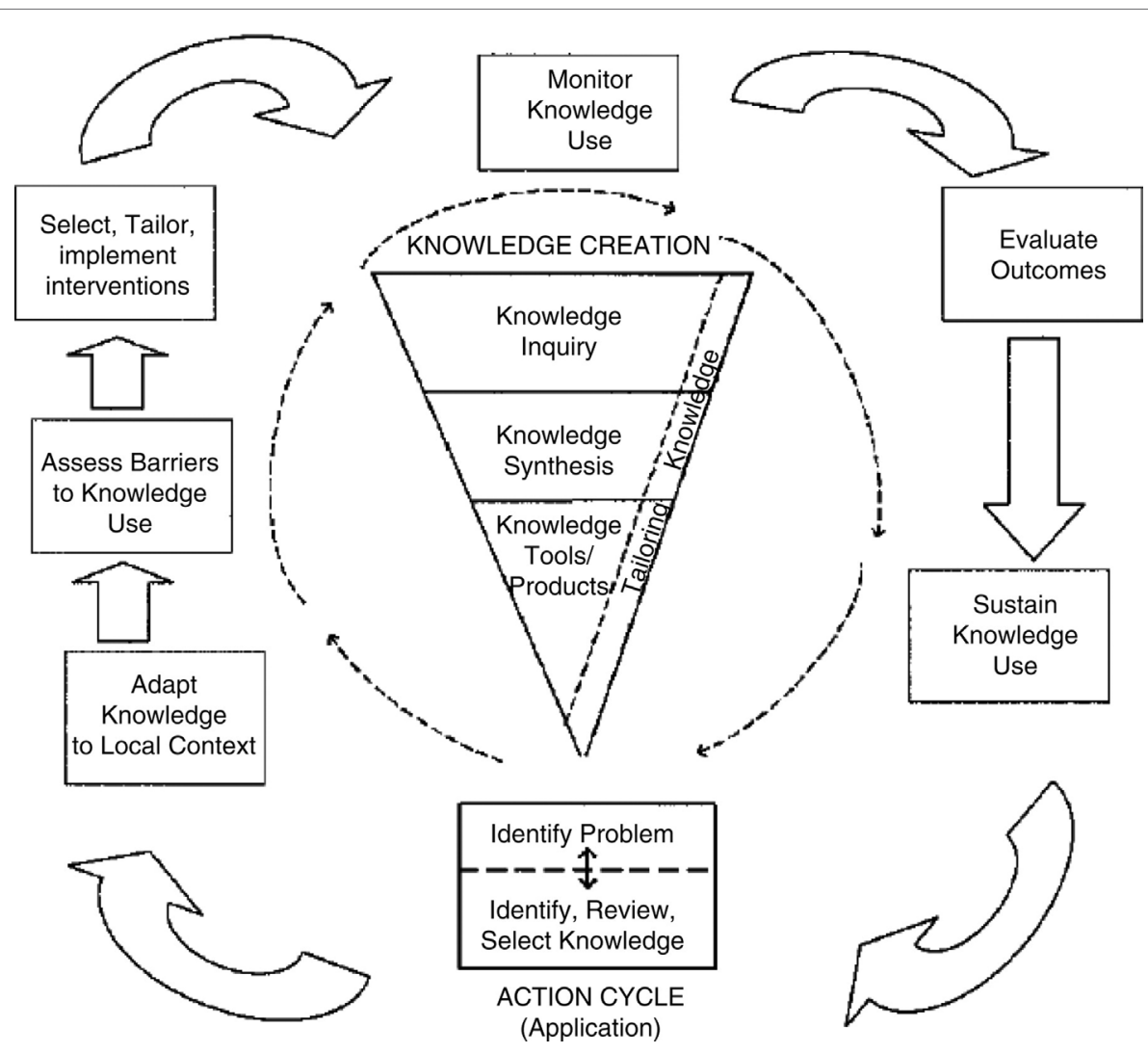

FIGURE 2 | Knowledge-to-action cycle. From Graham et al. (50) with permission. Copyright $\odot 2006$ The Alliance for Continuing Medical Education, the Society for Medical Education, the Society for Academic Continuing Medical Education, and the Council on CME, Association for Hospital Medical Education.

A number of theoretical models could be appropriate to guide an assessment of the challenges associated with decision aid implementation and to identify a strategy for implementation that is likely to be successful. Given the wide number of available in the literature, it is more important to apply an appropriate model well, than to identify the "perfect" model. The model we will use as the example to guide our discussion surrounding the implementation of breast cancer surgery decision aids is the knowledge to action cycle (Figure 2) (50). In our example, the fundamental knowledge-to-action gap being addressed is the idea that "decision aids work, but are rarely used." The knowledge-toaction cycle then outlines key steps to address this gap, including considering and/or adapting the intervention to the local context, assessing barriers to routine use, and selecting implementation strategies to address specific barriers.

\section{Adapt Knowledge to Local Context}

The local context in which an intervention will be implemented has a significant influence on the success of implementation and should be considered early in the planning process (27-30). In some clinical settings, it may be advantageous to tailor the intervention or the implementation to make it more suitable for a particular population or improve the fit within an organization's capacity. In other settings, additional implementation strategies may need to be incorporated. Adapting the implementation of an intervention to fit the local context can be an important step toward improving the success and sustainability of implementation. However, while adaptation may be desirable to maximize reach of the intervention, it is important to ensure that fidelity to the original intervention is maintained. A key step to accomplishing this is the identification of the core elements of an intervention and/or its implementation that is responsible for its effectiveness in achieving the intended outcome $(9,26,51)$. The core elements can be specific components of the intervention or the specific implementation strategies essential for successful delivery of the intervention. These core elements should remain unchanged during adaptation, with tailoring focusing instead on those elements thought to be modifiable $(9,26,51)$.

In our case of decision aid implementation, relevant aspects of the local context could include factors, such as financial resources of the institution, level of staffing within the specific clinic, and patient mix. These factors must be considered when developing an implementation process to ensure that implementation will be successful and sustainable. After considering these factors, examples of aspects of implementation that we would consider to be core elements critical for success would include the systematic identification of eligible patients prior to the clinical encounter (as opposed to rely on clinician identification of appropriate patients) 


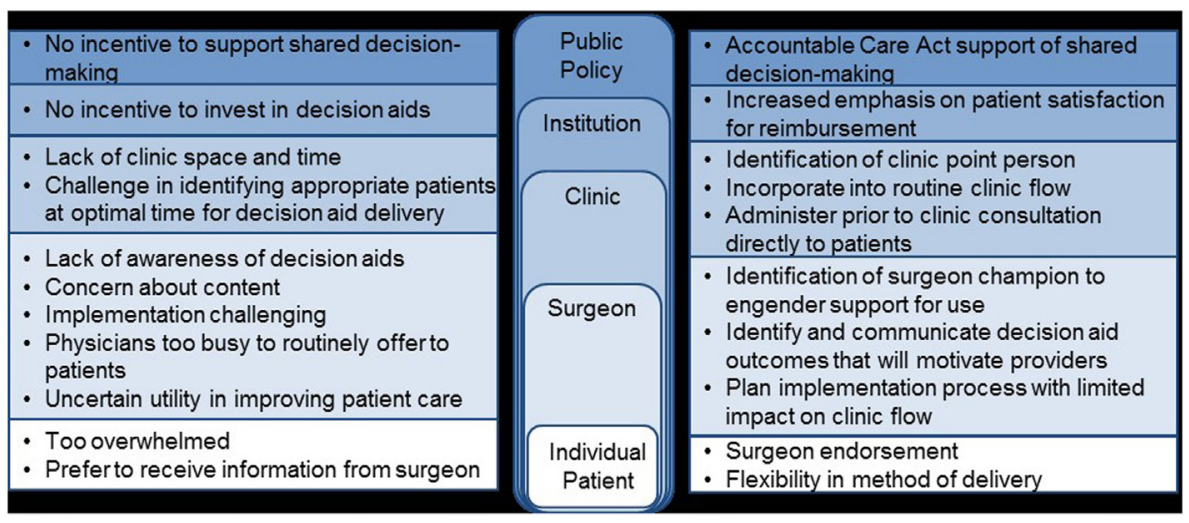

FIGURE 3 | Barriers and potential facilitators to use of a breast cancer surgery decision aid.

and administration of the decision aid outside of the surgery clinical setting (as opposed to ask the clinician to administer the decision aid themselves).

\section{Select, Tailor, and Implement Interventions}

Once the local context and barriers to use have been considered, implementation strategies must be selected to specifically address the known barriers. A useful tool for researchers in developing the package of implementation strategies needed is the compilation and categorization of strategies by Waltz et al. (17). In the case of decision aid implementation, we believe that "seamless" incorporation of the decision aid into routine clinical flow is critical for success. Specific challenges identified in our barrier assessment include limited clinic resources to administer decision aids, difficulty identifying appropriate patients in a timely manner, lack of surgeon buy-in, and patient preference to hear information from their surgeon (Figure 3). Although some clinics may be able to adjust their work flow to allow for decision aid administration, for many others, this is an insurmountable challenge and tailoring the logistics surrounding implementation will be necessary. One option to minimize the impact on the clinical workflow would be to utilize a decision aid administered directly to patients outside of the clinical encounter. Alternative decision aid formats, such as web-based decision aids, would be needed to accomplish this method of delivery efficiently and flexibility in method of deliver has been identified as a potential facilitator in one study (52-54). Challenges to identifying patients in a timely manner could be addressed by linking the identification of appropriate patients to scheduling of clinic visits or clinic intake calls; associating decision aid administration with a routine aspect of care already occurring will efficiently facilitate the systematic implementation of a decision aid (54). Utilization of a surgeon champion to engender support for the decision aid by other surgeons is critical for this type of intervention $(54,55)$. This individual can also be critical in preparing patients to be active participants in a decision aid intervention by endorsing the value of the decision aid as a way to enhance (and not subtract) from the future clinical encounter between patient and surgeon.

\section{Monitor Knowledge Use and Evaluate Outcomes}

As identified in the knowledge-to-action cycle, monitoring use and success of an intervention over time is an important step toward sustained use (50). Evaluation models, such as RE-AIM (8) and PRECEDE-PROCEEDE (25), provide a framework for identifying relevant constructs to judge success of an implementation process. In our case example of decision aid implementation, RE-AIM would be an appropriate evaluative model, focusing on constructs, such as the ability of the implementation to Reach all appropriate patients without introducing a systematic bias through the exclusion of certain patient populations, the Effectiveness of this method of decision aid delivery as a way to improve decision quality, and the acceptability of the intervention to patients and providers as a surrogate for future Adoption. Additional evaluative endpoints could include implementation fidelity. CFIR could also be used to evaluate implementation and explain success or lack of success (21). The various CFIR constructs can help to categorize areas where interventions fail or where specific challenges exist, and help to then identify additional potential implementation strategies. For example, in the case of decision aid implementation, if limited commitment by surgeons is identified as a barrier (characteristics of individuals construct), strategies that more strongly incorporate opinion leaders and champions could be included. If the process to implement the decision aid is perceived to be too complex for the local setting (intervention characteristics construct), adapting the implementation process to the needs of the local setting (while keeping the core elements consistent) could be explored.

A critical component of the knowledge-to-action cycle is feeding back the outcomes of these evaluations to guide iterative improvements to the implementation process. Regardless of the method utilized in monitoring the performance of the intervention, it is necessary to solicit feedback from stakeholders and actively seek out opportunities for improvement. Early identification of lapses in the implementation process can allow a timely response and create generalizable knowledge, which 
can inform the expansion of the intervention to other sites and clinical practices.

\section{CONCLUSION}

Decreasing the gap between the identification of beneficial interventions and the incorporation of these interventions into routine clinical care is an important step toward improving the quality of cancer care delivered. Successfully addressing this gap requires a systematic and theory-driven approach to the development and subsequent implementation of interventions. The growing field of implementation science has generated, and continues to generate, a broad base of generalizable knowledge surrounding how to successfully implement and sustain interventions. As we present in our clinical example, applying the concepts of implementation science to the unique challenges

\section{REFERENCES}

1. Institute of Medicine. Delivering high-quality cancer care: charting a new course for a system in crisis. In: Levit L, Balogh E, Nass S, Ganz PA, editors. Delivering High-Quality Cancer Care: Charting a New Course for a System in Crisis. Washington, DC: National Academies Press (US) (2013).

2. Agency for Healthcare Research and Quality. Translating Research into Practice (TRIP)-II: Fact Sheet. Rockville, MD: Agency for Healthcare Research and Quality (2001).

3. Nutbeam D. Improving the fit between research and practice in health promotion: overcoming structural barriers. Can J Public Health (1996) 87(Suppl 2):S18-23.

4. Green LW, Ottoson JM, Garcia C, Hiatt RA. Diffusion theory and knowledge dissemination, utilization, and integration in public health. Annu Rev Public Health (2009) 30:151-74. doi:10.1146/annurev.publhealth.031308.100049

5. Green LW. Making research relevant: if it is an evidence-based practice, where's the practice-based evidence? Fam Pract (2008) 25(Supp 1):i20-4. doi:10.1093/fampra/cmn055

6. Eccles M, Grimshaw J, Walker A, Johnston M, Pitts N. Changing the behavior of healthcare professionals: the use of theory in promoting the uptake of research findings. J Clin Epidemiol (2005) 58(2):107-12. doi:10.1016/j. jclinepi.2004.09.002

7. Greenhalgh T, Robert G, Macfarlane F, Bate P, Kyriakidou O. Diffusion of innovations in service organizations: systematic review and recommendations. Milbank Q (2004) 82(4):581-629. doi:10.1111/j.0887-378x.2004.00325.x

8. Glasgow RE, Vogt TM, Boles SM. Evaluating the public health impact of health promotion interventions: the RE-AIM framework. Am J Public Health (1999) 89(9):1322-7. doi:10.2105/AJPH.89.9.1322

9. Rabin BA, Brownson RC. Developing terminology for dissemination and implementation research. In: Brownson RC, Colditz GA, Proctor EK, editors. Dissemination and Implementation Research in Health: Translating Science to Practice. New York: Oxford University Press (2012). p. 23.

10. Eccles MP, Mittman BS. Welcome to implementation science. Implement Sci (2006) 1:1. doi:10.1186/1748-5908-1-1

11. National Institutes of Health. PAR-13-155: Dissemination and Implementation Research in Health (R01) (2015). Available from: http://grants.nih.gov/grants/ guide/pa-files/PAR-13-055.html

12. Bero LA, Grilli R, Grimshaw JM, Harvey E, Oxman AD, Thomson MA. Getting research findings into practice: closing the gap between research and practice: an overview of systematic reviews of interventions to promote the implementation of research findings. BMJ (1998) 317(7156):465-8. doi:10.1136/bmj.317.7156.465

13. Rubenstein LV, Pugh J. Strategies for promoting organizational and practice change by advancing implementation research. J Gen Intern Med (2006) 21(Suppl 2):S58-64. doi:10.1111/j.1525-1497.2006.00364.x

14. Leeman J, Baernholdt M, Sandelowski M. Developing a theory-based taxonomy of methods for implementing change in practice. J Adv Nurs (2007) 58(2):191-200. doi:10.1111/j.1365-2648.2006.04207.x associated with cancer care for women can improve the quality of the cancer care we deliver.

\section{AUTHOR CONTRIBUTIONS}

$\mathrm{HN}$ and TA were responsible for concept development, literature review, and primary manuscript writing. CG participated in concept development and review of the manuscript.

\section{FUNDING}

$\mathrm{HN}$ is supported through the Building Interdisciplinary Research Careers in Women's Health Scholar Program (NIH K12 HD055894). TA receives support from the University of Wisconsin Surgical Oncology Research Training Program (T32 CA090217).

15. Michie S, Fixsen D, Grimshaw JM, Eccles MP. Specifying and reporting complex behaviour change interventions: the need for a scientific method. Implement Sci (2009) 4(1):40. doi:10.1186/1748-5908-4-40

16. Powell BJ, Waltz TJ, Chinman MJ, Damschroder LJ, Smith JL, Matthieu MM, et al. A refined compilation of implementation strategies: results from the expert recommendations for implementing change (ERIC) project. Implement Sci (2015) 10:21. doi:10.1186/s13012-015-0209-1

17. Waltz TJ, Powell BJ, Matthieu MM, Damschroder LJ, Chinman MJ, Smith JL, et al. Use of concept mapping to characterize relationships among implementation strategies and assess their feasibility and importance: results from the expert recommendations for implementing change (ERIC) study. Implement Sci (2015) 10(1):109. doi:10.1186/s13012-015-0295-0

18. Nilsen P. Making sense of implementation theories, models and frameworks. Implement Sci (2015) 10:53. doi:10.1186/s13012-015-0242-0

19. Proctor EK, Powell BJ, McMillen JC. Implementation strategies: recommendations for specifying and reporting. Implement Sci (2013) 8:139. doi:10.1186/1748-5908-8-139

20. Tabak RG, Khoong EC, Chambers DA, Brownson RC. Bridging research and practice: models for dissemination and implementation research. Am J Prev Med (2012) 43(3):337-50. doi:10.1016/j.amepre.2012.05.024

21. Damschroder LJ, Aron DC, Keith RE, Kirsh SR, Alexander JA, Lowery JC. Fostering implementation of health services research findings into practice: a consolidated framework for advancing implementation science. Implement Sci (2009) 4:50. doi:10.1186/1748-5908-4-50

22. Jacobson N, Butterill D, Goering P. Development of a framework for knowledge translation: understanding user context. J Health Serv Res Policy (2003) 8(2):94-9. doi:10.1258/135581903321466067

23. Murray E, Treweek S, Pope C, MacFarlane A, Ballini L, Dowrick C, et al. Normalisation process theory: a framework for developing, evaluating and implementing complex interventions. BMC Med (2010) 8:63. doi:10.1186/1741-7015-8-63

24. Harris JR, Cheadle A, Hannon PA, Forehand M, Lichiello P, Mahoney E, et al. A framework for disseminating evidence-based health promotion practices. Prev Chronic Dis (2012) 9:E22. doi:10.5888/pcd9.120126

25. Green LW, Kreuter MW. Health Program Planning: An Educational and Ecological Approach. New York, NY: McGraw-Hill (2005).

26. Kilbourne AM, Neumann MS, Pincus HA, Bauer MS, Stall R. Implementing evidence-based interventions in health care: application of the replicating effective programs framework. Implement Sci (2007) 2:42. doi:10.1186/1748-5908-2-42

27. Cohen DJ, Crabtree BF, Etz RS, Balasubramanian BA, Donahue KE, Leviton LC, et al. Fidelity versus flexibility: translating evidence-based research into practice. Am J Prev Med (2008) 35(5 Suppl):S381-9. doi:10.1016/j. amepre.2008.08.005

28. Keith RE, Hopp FP, Subramanian U, Wiitala W, Lowery JC. Fidelity of implementation: development and testing of a measure. Implement Sci (2010) 5(1):99. doi:10.1186/1748-5908-5-99

29. Tomoaia-Cotisel A, Scammon DL, Waitzman NJ, Cronholm PF, Halladay JR, Driscoll DL, et al. Context matters: the experience of 14 research teams in 
systematically reporting contextual factors important for practice change. Ann Fam Med (2013) 11(Suppl 1):S115-23. doi:10.1370/afm.1549

30. Glasgow RE, Chambers D. Developing robust, sustainable, implementation systems using rigorous, rapid and relevant science. Clin Transl Sci (2012) 5(1):48-55. doi:10.1111/j.1752-8062.2011.00383.x

31. Abraham C, Johnson BT, de Bruin M, Luszczynska A. Enhancing reporting of behavior change intervention evaluations. J Acquir Immune Defic Syndr (2014) 66(Suppl 3):S293-9. doi:10.1097/QAI.0000000000000231

32. Hoffmann TC, Glasziou PP, Boutron I, Milne R, Perera R, Moher D, et al. Better reporting of interventions: template for intervention description and replication (TIDieR) checklist and guide. BMJ (2014) 348:g1687. doi:10.1136/ bmj.g1687

33. Mohler R, Bartoszek G, Kopke S, Meyer G. Proposed criteria for reporting the development and evaluation of complex interventions in healthcare (CReDECI): guideline development. Int J Nurs Stud (2012) 49(1):40-6. doi:10.1016/j.ijnurstu.2011.08.003

34. Schulz R, Czaja SJ, McKay JR, Ory MG, Belle SH. Intervention taxonomy (ITAX): describing essential features of interventions. Am J Health Behav (2010) 34(6):811-21. doi:10.5993/AJHB.34.6.15

35. von Elm E, Altman DG, Egger M, Pocock SJ, Gotzsche PC, Vandenbroucke JP, et al. The strengthening the reporting of observational studies in epidemiology (STROBE) statement: guidelines for reporting observational studies. Int J Surg (2014) 12(12):1495-9. doi:10.1016/j.ijsu.2014.07.013

36. Ogrinc G, Davies L, Goodman D, Batalden P, Davidoff F, Stevens D. SQUIRE 2.0 (Standards for QUality Improvement Reporting Excellence): revised publication guidelines from a detailed consensus process. BMJ Qual Saf (2015). doi:10.1136/bmjqs-2015-004411

37. Ogrinc G, Mooney SE, Estrada C, Foster T, Goldmann D, Hall LW, et al. The SQUIRE (Standards for QUality Improvement Reporting Excellence) guidelines for quality improvement reporting: explanation and elaboration. Qual Saf Health Care (2008) 17(Suppl 1):i13-32. doi:10.1136/qshc.2008.029058

38. Pinnock H, Epiphaniou E, Sheikh A, Griffiths C, Eldridge S, Craig P, et al. Developing standards for reporting implementation studies of complex interventions (StaRI): a systematic review and e-Delphi. Implement Sci (2015) 10:42. doi:10.1186/s13012-015-0235-Z

39. Trikalinos TA, Wieland LS, Adam GP, Zgodic A, Ntzani EE. Decision Aids for Cancer Screening and Treatment. Comparative Effectiveness Reviews 145. Rockville, MD: Agency for Healthcare Research and Quality (2014).

40. O'Connor AM, Bennett CL, Stacey D, Barry M, Col NF, Eden KB, et al. Decision aids for people facing health treatment or screening decisions. Cochrane Database Syst Rev (2009) (3):CD001431. doi:10.1002/14651858. CD001431.pub2

41. Oshima Lee E, Emanuel EJ. Shared decision making to improve care and reduce costs. N Engl J Med (2013) 368(1):6-8. doi:10.1056/NEJMp1209500

42. Ashraf AA, Colakoglu S, Nguyen JT, Anastasopulos AJ, Ibrahim AM, Yueh $\mathrm{JH}$, et al. Patient involvement in the decision-making process improves satisfaction and quality of life in postmastectomy breast reconstruction.J Surg Res (2013) 184(1):665-70. doi:10.1016/j.jss.2013.04.057

43. Mandelblatt J, Kreling B, Figeuriedo M, Feng S. What is the impact of shared decision making on treatment and outcomes for older women with breast cancer? J Clin Oncol (2006) 24(30):4908-13. doi:10.1200/JCO.2006.07.1159
44. Molenaar S, Sprangers MA, Rutgers EJ, Luiten EJ, Mulder J, Bossuyt PM, et al. Decision support for patients with early-stage breast cancer: effects of an interactive breast cancer $\mathrm{CDROM}$ on treatment decision, satisfaction, and quality of life. J Clin Oncol (2001) 19(6):1676-87.

45. Street RL Jr, Voigt B, Geyer C Jr, Manning T, Swanson GP. Increasing patient involvement in choosing treatment for early breast cancer. Cancer (1995) 76(11):2275-85. doi:10.1002/1097-0142(19951201)76:11<2275::AID-CNCR2820761115>3.0.CO;2-S

46. Waljee JF, Rogers MA, Alderman AK. Decision aids and breast cancer: do they influence choice for surgery and knowledge of treatment options? J Clin Oncol (2007) 25(9):1067-73. doi:10.1200/JCO.2006.08.5472

47. Whelan T, Levine M, Gafni A, Sanders K, Willan A, Mirsky D, et al. Mastectomy or lumpectomy? Helping women make informed choices. J Clin Oncol (1999) 17(6):1727-35.

48. Elwyn G, Scholl I, Tietbohl C, Mann M, Edwards AG, Clay C, et al. "Many miles to go...": a systematic review of the implementation of patient decision support interventions into routine clinical practice. BMC Med Inform Decis Mak (2013) 13(Suppl 2):S14. doi:10.1186/1472-6947-13-S2-S14

49. Sinha G. Decision aids help patients but still are not widely used. J Natl Cancer Inst (2014) 106(7):dju224. doi:10.1093/jnci/dju224

50. Graham ID, Logan J, Harrison MB, Straus SE, Tetroe J, Caswell W, et al. Lost in knowledge translation: time for a map? J Contin Educ Health Prof (2006) 26(1):13-24. doi:10.1002/chp.47

51. Fixsen D, Naoom S, Blase K, Friedman R, Wallace F. Implementation Research: A Synthesis of the Literature. Tampa, FL: University of South Florida, Louis de la Parte Florida Mental Health Institute, The National Implementation Research Network (FMHI Publication \#231) (2005).

52. Elwyn G, Rix A, Holt T, Jones D. Why do clinicians not refer patients to online decision support tools? Interviews with front line clinics in the NHS. BMJ Open (2012) 2(6):e001530. doi:10.1136/bmjopen-2012-001530

53. Hoffman AS, Volk RJ, Saarimaki A, Stirling C, Li LC, Harter M, et al. Delivering patient decision aids on the Internet: definitions, theories, current evidence, and emerging research areas. BMC Med Inform Decis Mak (2013) 13(Suppl 2):S13. doi:10.1186/1472-6947-13-S2-S13

54. Silvia KA, Sepucha KR. Decision aids in routine practice: lessons from the breast cancer initiative. Health Expect (2006) 9(3):255-64. doi:10.1111/j.1369-7625.2006.00393.x

55. Silvia KA, Ozanne EM, Sepucha KR. Implementing breast cancer decision aids in community sites: barriers and resources. Health Expect (2008) 11(1):46-53. doi:10.1111/j.1369-7625.2007.00477.x

Conflict of Interest Statement: The authors declare that the research was conducted in the absence of any commercial or financial relationships that could be construed as a potential conflict of interest.

Copyright (๑ 2016 Adesoye, Greenberg and Neuman. This is an open-access article distributed under the terms of the Creative Commons Attribution License (CC BY). The use, distribution or reproduction in other forums is permitted, provided the original author(s) or licensor are credited and that the original publication in this journal is cited, in accordance with accepted academic practice. No use, distribution or reproduction is permitted which does not comply with these terms. 